\title{
O REFERENCIAL CURRICULAR DA EDUCAÇÃO FÍSICA DO ESTADO DO RIO GRANDE DO SUL: UMA ANÁLISE QUALITATIVA DE CONTEÚDO
}

\author{
Luis Eugênio Martiny \\ Universidade Federal da Paraíba, João Pessoa, Paraíba, Brasil \\ Samara Queiroz do Nascimento Florêncio \\ Universidade Federal da Paraíba, João Pessoa, Paraíba, Brasil \\ Pierre Normando Gomes-da-Silva \\ Universidade Federal da Paraíba, João Pessoa, Paraíba, Brasil
}

\begin{abstract}
Resumo: O artigo teve por finalidade analisar o referencial curricular do Rio Grande do Sul para o componente curricular Educação Física. Esta análise incidiu sobre o próprio documento e a discussão ocorreu a partir da estratégia de emparelhamento, associando os núcleos de sentido com a teoria crítica do currículo da área. O documento constituise num constructo teórico-metodológico inovador e conectado com as exigências contemporâneas para uma educação básica de qualidade na medida em que propôs uma organização das matérias com critérios para seleção e tratamento dos saberes de modo mais plural, generalista e crítico. Entretanto, nas relações de poder que compõem a formação de currículos, o referencial poderá se tornar um manual didático e que sinalize um possível discurso dominante.
\end{abstract}

Palavras-chave: Cultura; Educação; Currículo

\section{Introdução}

No decorrer da história a Educação Física (EF), como área de conhecimento, ela sempre entrou em conflito em relação às delimitações do seu campo de intervenção. No contexto escolar, como disciplina curricular ela sempre foi (e talvez ainda seja) vista muito mais como atividade prática, executora de exercícios físicos para $o$ desenvolvimento motor dos alunos. Para as 'autoridades', as aulas de EF sempre foram entendidas como um tempo pedagógico do qual se poderia lançar mão para a realização de outras atividades escolares (BRACHT, 2003b).

No campo da legalidade, conquistou a condição de componente curricular indispensável à formação integral dos alunos por meio da Lei 9394/96 (BRASIL, 1996) e da lei complementar 10.328/01 (BRASIL, 2001). Em contrapartida é no campo da legitimidade que ainda busca o seu reconhecimento como área de conhecimento. E essa é uma das constantes queixas dos professores em relação às outras disciplinas que compõem o currículo escolar (GONZÁLEZ, 2006). A atribuição a esta falta de legitimidade da área perante o universo escolar. Em um sentido mais abrangente, diz respeito aos saberes necessários que deverão ser tematizados pela disciplina e, por conseguinte, a uma possível falta de proposta pedagógica consistente para $\mathrm{o}$ desenvolvimento da EF no âmbito escolar. Problemas estes relacionados a uma consistência interna da área que recai na produção de justificativas de sua presença como componente curricular no cenário escolar. 
Desta feita, parte-se do pressuposto em compreender o currículo como artefato sócio-cultural (MOREIRA; TADEU DA SILVA, 1994), portanto, como uma produção contextual determinada por suas condições históricas e implicada em relações de poder. Sendo assim, observa-se que a forma de organização do conhecimento escolar da educação física, ao longo da sua história na educação brasileira, desde os anos 20 do século passado, padece de inúmeras restrições, do ponto de vista da formação de um sujeito emancipado.

Para Oliveira (1999) a área ainda não possui uma organização e uma sistematização de conteúdos a serem desenvolvidos nas escolas. Isto faz com que esta falta de estrutura pedagógica curricular coloque a disciplina dentro de uma ação pedagógica com fim em si mesma, sem sequência ao longo dos anos escolares. Por freqüentemente detectar a falta de uma progressão lógica ou de uma sequência nas experiências escolares (NAHAS, 2006), e quiçá pela busca desta legitimação escolar, alguns autores dentre os quais, Grespan (2002), González (2006), Souza Júnior et al. (2005) entre outros, tem apresentado propostas para o desenvolvimento/ sistematização da EF ao longo dos anos escolares. Estas propostas vão desde dimensões mais holísticas, ao qual englobam um conjunto de saberes (unidades programáticas), para dimensões mais restritas que delimitam sobre um único eixo temático, a serem desenvolvidas pelo componente curricular no contexto escolar.

Complementarmente a esta necessidade de estruturação, alguns estados (SP, PR, RJ, ES, SE, MS, AC), após a elaboração dos Parâmetros Curriculares Nacionais (BRASIL, 1997), têm lançado referenciais teóricos para o desenvolvimento das disciplinas que compõem o seu currículo escolar. Estes referenciais têm por base, servirem de aporte aos professores da Rede Estadual e/ou Municipal nos seus processos de intervenção pedagógica. Surgem como orientações curriculares para o desenvolvimento das disciplinas ao longo dos anos escolares.

Em termos do contexto sócio-histórico, essas reformas curriculares, incentivada pelos PCNs e órgãos internacionais, nos estados tiveram o objetivo de inculcar valores e hábitos "adequados" às transformações econômicas, sociais e culturais que estavam ocorrendo no processo de consolidação de um modelo de capitalismo da eficiência social. Contudo, como o currículo é um terreno de relações de poder na produção simbólica da cultura, portanto num conflito entre diferentes interesses, essas reformas foram fundamentadas em fontes teóricas, para além do funcionalismo estrutural, que foram: fenomenologia, etnometodologia, interacionismo simbólico e um marxismo reelaborado.

O Estado do Rio Grande do Sul (RS), engajado nesta proposição construiu os seus referenciais - Lições do Rio Grande (RIO GRANDE DO SUL, 2009) - objetivando disseminá-los na sua rede escolar. Nestes referenciais, dentre as diversas disciplinas que compõem o currículo escolar, consta uma proposta para o desenvolvimento da EF da $5^{\mathrm{a}}$ serie ( $6^{\circ}$ ano) do Ensino Fundamental II a $3^{\mathrm{a}}$ série $\left(3^{\circ}\right.$ ano) do Ensino Médio (GONZÁLEZ; FRAGA, 2009).

O presente artigo, no mesmo instante que reconhece o desafio de construção de uma proposta pedagógica a ser desenvolvida ao longo de anos escolares, objetiva dialogar, por meio de uma análise descritiva, com tal referencial, produzindo uma apreciação argumentativa acerca da proposta elaborada.

Pensar a Prática, Goiânia, v. 14, n. 1, p. 1-14, jan./abr. 2011 


\section{Metodologia}

O estudo caracterizou-se como uma pesquisa documental, de análise qualitativa de conteúdo, utilizando como a estratégia de Emparelhamento (pattern-matching), segundo Laville; Dionne (1999, p.227) sobre o referencial curricular "Lições do Rio Grande", mais especificamente, na área das línguas, códigos e suas tecnologias, volume II, componente curricular Educação Física (GONZÁLEZ; FRAGA, 2009). A análise esta focalizada em associar os núcleos de significado do documento, a estrutura funcional e os saberes propostos, com um modelo teórico crítico de currículo de EF (BETTI, 2005; NEGRELLI, 2005; GONZÁLEZ, 2006; BRACHT, 2003b), se circunscrevendo como desdobramento da Nova Sociologia do Currículo (FORQUIN, 1993).

Para iniciar as argumentações sobre a estrutura-funcional do referencial curricular e sobre os saberes abordados foi adotada a prerrogativa de fazê-lo sobre os cinco itens que o compõem. Estes itens são: 1) Competências da EF na Educação Básica; 2) Princípios orientadores do referencial curricular da EF; 3) Organização dos Referenciais Curriculares nos seus subtemas - que são: 3.1) Temas estruturadores; 3.2) Progressão curricular; 3.3) Tempo disponível e tempo necessário - 4) Mapas de competências e conteúdos por temas e subtemas; 5) Estratégias para o desenvolvimento das competências.

\section{Análise qualitativa de conteúdo}

A elaboração do referencial curricular partiu da necessidade de cumprimento de algumas metas estipuladas pelo movimento Todos pela Educação, especificamente em relação à meta de $\mathrm{n}^{\mathrm{o}} 3$, cujo objetivo é identificar os conteúdos sociais adequados para serem aprendidos em cada série do Ensino Fundamental e Médio na escola ${ }^{1}$. O estado do RS, procurando realizar aproximações ao cumprimento desta meta, acabou por constituir um grupo de especialistas para elaborar os referencias curriculares do seu estado. Esta comissão foi composta por 22 professores de inúmeras instituições de ensino superior do estado e professores da rede estadual de ensino (colaboradores).

Com a finalidade de apurar a qualidade do ensino prestado nas escolas gaúchas, melhorar o sistema educacional do estado, aprimorar o processo de ensinoaprendizagem e ofertar norteadores para a construção de propostas e estratégias de intervenção pedagógica, a Secretaria de Educação do Estado do RS, terminou por lançar, no ano de 2009, para os professores da sua rede escolar, as bases teóricometodológicas dos componentes curriculares que compõem o seu sistema de ensino básico. Os cadernos denominados "Lições do Rio Grande" além de conter os princípios e diretrizes curriculares para a educação no estado, apresentam um conjunto de saberes, habilidades e competências que devem ser desenvolvidos ao longo dos anos escolares nas diferentes disciplinas que compõem o seu currículo escolar.

No que concerne ao Componente Curricular EF, integrante da área de linguagens, códigos e suas tecnologias, dois foram os professores especialistas encarregados na elaboração do material ${ }^{2}$. Ancorados em uma matriz pós-estruturalista, cujo foco está no conteúdo e no contexto da linguagem, mediante as relações de poder

\footnotetext{
${ }^{1}$ Este movimento teve o seu início em setembro de 2006 e tem como principal missão "contribuir para a efetivação do direito de todas as crianças e jovens à Educação Básica de qualidade até 2022" (Texto extraído da pagina web do movimento: http://www.todospelaeducacao.org.br/institucional)
}

Pensar a Prática, Goiânia, v. 14, n. 1, p. 1-14, jan./abr. 2011 
específicas, e posicionando-se para uma perspectiva progressista da área, eles procuraram construir um material que caminhe para uma visão crítica da EF na escola.

Trata-se de um documento que manifesta a aspiração de fixar a EF como um componente curricular que se localize para além de uma disciplina exclusivamente prática, conforme definia o artigo primeiro do decreto $n^{\circ} 69.450 / 71^{3}$. Que mostra suas pretensões em relação a este componente, com seus conteúdos, inclusive teóricos que deveriam ser tematizados ao longo dos anos escolares. Estas intenções vão para além do interpretar, traduzir e discutir as diferentes linguagens do se-movimentar humano nas suas múltiplas manifestações corporais emergidas na cultura geral humana, e se alicerçam na formação de um aluno/sujeito crítico e criativo, que possa intervir ativamente no contexto em que este esteja inserido.

A EF escolar tem se caracterizado por ser uma prática pedagógica de intervenção direta na sociedade (BRACHT, 2003a). Na escola, como componente curricular, ela passa a ser "responsável pela apreensão (no sentido de constatação, demonstração, compreensão e explicação) de uma dimensão da realidade social, na qual o aluno está inserido" (CASTELLANI FILHO, 1998, p. 53-54).

Ao situá-la acerca desta apreensão de uma dimensão da realidade social, dentro de uma perspectiva humanista, didático-pedagógico e histórico-social, o desenvolvimento de certas competências poderá contribuir para a formação crítica dos alunos. Uma formação humana pautada nos princípios da cidadania (inclusão, alteridade e de acesso igual à informação por todos) da reflexão crítica e criativa e da autonomia. Nesta concepção de formar cidadãos engajados em um projeto de transformação social o referido referencial curricular (GONZÁLEZ; FRAGA, 2009) apresenta um conjunto de competências ao qual pretende desenvolver ao longo dos anos escolares. Deste conjunto de competências, três grupos podem ser destacados.

O primeiro deles diz respeito ao desenvolvimento de competências para melhor compreender e conhecer as diversas manifestações acerca da Cultura Corporal de Movimento (CCM) e as produções culturais acerca do corpo e do movimento que os alunos poderão receber informações para tematizar tais assuntos. Num segundo grupo está à competência para analisar as experiências corporais contextualizadas e a utilização da linguagem corporal como expressão comunicativa.

Estas competências estão atreladas ao aluno conseguir interagir no meio ao qual está inserido, fazendo parte dele podendo desencadear um pensamento crítico sobre essa interação. E, por fim, um terceiro grupo que está focalizado na interferência da produção cultural em que se objetiva preservar as manifestações da CCM. Resgatar as práticas corporais tradicionais, contextualizando-as no cenário atual.

O desenvolvimento destes três grupos de competências como proposição do referencial curricular, para os seus autores abrange três finalidades: 1) a superioridade da atuação escolar (saber escolar) sobre a ação cultural; 2) a cultivação da cultura, como matéria prima do mundo da vida e não como indústria cultural; 3 ) a prática refletida e contextualizada.

\footnotetext{
${ }^{2}$ Estes especialistas foram os professores Alex Branco Fraga, Professor Adjunto da Universidade Federal do Rio Grande do Sul - UFRGS e Fernando Jaime González, Professor Adjunto da Universidade Regional do Noroeste do estado do Rio Grande do Sul - UNIJUÍ

${ }^{3}$ A redação completa: “a Educação Física, atividade que por seus meios, processos e técnicas, desperta, desenvolve e aprimora forças físicas, morais, cívicas, psíquicas e sociais do educando, constitui um dos fatores básicos para conquista das finalidades da educação nacional” (BRASIL, 1971)
}

Pensar a Prática, Goiânia, v. 14, n. 1, p. 1-14, jan./abr. 2011 
Em relação a estes três grupos de competências e acerca de suas três finalidades, é importante destacar que "o ser humano como sujeito do conhecimento, não tem acesso direto a compreensão de mundo. Para isto, ele necessita de mediações provenientes da cultura e que desempenham a função de recortes do real". (SILVA, 2005, p.90). Neste sentido, como propriamente exposto no referencial, é o desenvolvimento destas competências (grupos e finalidades) que permitirão ao aluno a apreensão críticoreflexivo deste patrimônio da sociedade.

Estas competências oferecem a este aluno uma possível condição de leitura crítica sobre o mundo da vida. O desenvolvimento destas estruturas é o que possibilita a constituição do Ser Humano. Uma possibilidade que surge no confrontamento do saber popular com o conhecimento científico e o saber escolar. O que poderá instigar o aluno a ultrapassar o senso comum e construir formas mais elaboradas de pensamento (COLETIVO DE AUTORES, 1992).

A escolha por trabalhar pelo desenvolvimento de competências tem os seus interesses alicerçados na ruptura de um currículo técnico-instrumental. Ao trabalhar com os conceitos de competências se busca minimizar as divisões disciplinares, diminuir os programas de ensino, trabalhar com um número mais limitado de noções disciplinares na possibilidade de ampliar o tempo para o exercício da transferência ${ }^{4} \mathrm{e}$ consequentemente da mobilização dos saberes (PERRENOUD, 2000).

No que diz respeito aos princípios orientadores, o referencial curricular gaúcho expõe a EF como componente curricular, ao qual tem na dimensão cultural do corpo e do movimento humano a sua especificidade. Compete a ela possibilitar uma tematização, ressignificação, reprodução e transformação desta Cultura. Neste sentido, é importante ressaltar que:

\begin{abstract}
se a educação física pretende ser uma disciplina escolar [componente curricular] com status semelhante ao adquirido pelas demais, precisa dizer a que veio, o que ensina. Enquanto engasgar cada vez que for questionada sobre o que pode ensinar, será uma disciplina marginal (FREIRE; SCAGLIA, 2003 p. 35)
\end{abstract}

É o que o referido referencial vem tentando demonstrar'. Para tentar 'dizer a que veio' o referencial curricular gaúcho definiu como objeto de estudo o corpo e o movimento humano, enquanto suas manifestações culturais e representações sociais. Não obstante, a cultura corporal de movimento (CCM) é hoje o objeto do qual trata a educação física de maior consenso dentro da área $(\mathrm{PICH}, 2005)^{6}$. Este consenso se estabelece, inicialmente, por ela constituir uma parte da totalidade da cultura humana. Ao evidenciar que é na dimensão/valoração da cultura que se justifica todo o empreendimento educativo (FORQUIN, 1993), a CCM passa a ser considerada um dos maiores patrimônios da sociedade contemporânea.

Ao contextualizar esta CCM como sendo o objeto de estudo da EF escolar, é importante e faz-se necessário primeiramente romper com as teorias tradicionais da Educação, com suas visões reducionistas de cultura, corpo e movimento. Teorias estas

\footnotetext{
${ }^{4}$ Para o autor esta transferência significa transpor e combinar saberes, inventando uma estratégia original para resolver problemas em situações complexas.

${ }^{5}$ Para Rezer; Fensterseifer (2008) a legitimidade da docência na EF também perpassa por estas questões de saber e ter o que ensinar, de forma articulada e organizada.

${ }^{6}$ Uma melhor discussão sobre os termos Cultura Corporal, Cultura de movimento ou Cultura Corporal de movimento, pode ser vista em Bracht (2005).
}

Pensar a Prática, Goiânia, v. 14, n. 1, p. 1-14, jan./abr. 2011 
influenciadas pelo cientificismo da sociedade moderna ao qual se constituía pela racionalidade técnica e que não levavam em conta a realidade, as relações sócioculturais, as contradições e conflitos presentes na sociedade. Estas teorias são encaradas como neutras aos problemas sociais e a - históricas. A dimensão cultural não é considerada. O corpo é visto como um objeto dentro da sua dimensão biológicofisiológica a ser instrumentalizado. E o movimento é visto como algo mecânico e de reprodução tecnicista.

A incorporação da CCM como objeto de estudo da área e foco do referencial, já caracteriza, de certa forma, a ruptura desta EF reacionária, instrumental e utilitarista (influenciada pelas teorias tradicionais) para uma EF crítica, revolucionária, progressista e emancipatória. Ao estabelecer o desenvolvimento da EF na sua dimensão cultural supera de imediato a perspectiva reducionista de concepção de ser humano (PICH, 2005). Nesta perspectiva, o professor de EF, além de superar o ensino do gesto motor somente, começa a "problematizar, interpretar, relacionar, compreender com seus alunos as amplas manifestações da cultural corporal, de tal forma que os alunos compreendam os sentidos e significados impregnados nas práticas corporais" (DARIDO, 2001, p. 20).

Isto porque tal dimensão cultural passa a ser vista como um processo contínuo e dinâmico, repleto de pluralidade de significados, na qual os homens empreendem o tempo todo, em um constante processo de manipulação (DAOLIO, 2005). O corpo passa a não ser mais visto como um objeto/instrumento mais sim um corpo-sujeito. Um corpo plenamente investido de sentido e significado. Um corpo fruto de uma construção cultural, social e histórica.

O movimento dentro desta perspectiva passa a ser encarado não mais como um conjunto de ações físicas ou coordenativas, mas sim, possuidor de uma linguagem, que traz uma expressão corporal na realização de seu movimento. Tem suas funções expressivas, adaptativas, comunicativas, exploratórias, repletos de subjetividade.

Sendo assim, a educação física, nessa expectativa, cumpre sua função escolar de favorecer a socialização ao provocar o desenvolvimento de conhecimentos, afetos, habilidades e comportamentos que permitem a incorporação dos sujeitos da educação no mundo civil, no âmbito da liberdade de consumo, de escolha e participação política, da liberdade e responsabilidade da vida familiar e do mundo do trabalho. (SACRISTAN; PEREZ GÓMEZ, 2000).

A conseqüência maior desta incorporação da CCM como objeto da EF escolar e, por conseguinte, do referido referencial, é o rompimento do caráter instrumental da disciplina ${ }^{7}$. A área avança neste sentido, "do fazer corporal para um saber sobre o movimentar-se do ser humano" (BETTI, 2005, p 147). Esta ampliação do saber fazer para formas mais elaboradas de saber (conceitual, atitudinal) entendemos ser um avanço significativo proposto no referencial curricular gaúcho. "É importante salientar que a $\mathrm{EF}$, ao longo de sua história, ao contrário das demais disciplinas escolares, priorizou os conteúdos numa dimensão quase que exclusivamente procedimental, o saber fazer e não o saber sobre a cultura corporal ou como se deve ser." (DARIDO, 2005, p. 98)

Ao romper com uma aula voltada para a execução de movimento para uma aula em que se valorize e se tematize o movimento humano como linguagem corporal, isto possibilita algumas implicações. Uma das conseqüências disto esta no fato de fazer da aula "um lugar de aprender coisas e não apenas o lugar onde àqueles que dominam

\footnotetext{
${ }^{7}$ Esta ruptura gera não somente a mudança na área (enquanto componente curricular), mas também no perfil do profissional que orienta e mediatiza tal conhecimento. Ver estudo de González (2008)
}

Pensar a Prática, Goiânia, v. 14, n. 1, p. 1-14, jan./abr. 2011 
técnicas rudimentares de um determinado esporte vão 'praticar' o que sabem, enquanto aqueles que não sabem continuam no mesmo lugar" (SOARES, 1996, p. 11).

$O$ referencial traz uma proposta consistente para o desenvolvimento da EF como disciplina curricular responsável por uma fatia de entendimento da sociedade e, por conseguinte, de mundo. Mais especificamente, da análise crítico-reflexiva do movimento humano em todas as suas diferentes manifestações. Manifestações estas que são geradas na própria dimensão cultural humana (DAOLIO, 2005). No referencial curricular, é o conjunto destas manifestações corporais, provindas das práticas sociais, como construções históricas, que são desenvolvidas e tematizadas.

Nesta perspectiva, as manifestações culturais e representações sociais gerados por meio do se-movimentar humano é que se tornaram os conteúdos a serem desenvolvidos no âmbito escolar. Conteúdos estes que têm relevância cultural e validez social, pois formam parte dos valores significativos da cultura. (ROZENGARDT, 2005).

Não no sentido de apenas reproduzir o processo de socialização de um conhecimento consolidado (ciência, filosofia, cultura, arte...), mas favorecer a mediação crítica da utilização desse conhecimento, que pode ser dado por meio de dois procedimentos, conforme Sacristan e Perez Gómez (2000): o desenvolvimento radical da função compensatória (fomentar a pluralidade de formas de viver, pensar e sentir) e a reconstrução do conhecimento e da experiência (estimular a participação ativa e crítica dos alunos nas diferentes tarefas que se desenvolvem na aula).

No referencial estes conteúdos (saberes e conhecimentos) são apresentados em dois conjuntos de temas estruturadores (práticas corporais sistematizadas e as representações sociais da Cultura Corporal de movimento). O primeiro deles se divide em sete subtemas i) esporte; ii) ginástica; iii) jogo motor; iv) lutas; v) práticas corporais expressivas vi) práticas corporais junto à natureza e vii) atividades aquáticas. Já o segundo se divide em dois subtemas: i) práticas corporais e sociedade e ii) práticas corporais e saúde. Estes subtemas se dividem em eixos temáticos (saberes corporais e saberes conceituais) e estes se dividem em sub-eixos. Dentro do eixo temático, saberes corporais, os subeixos são: saber praticar e saber para conhecer. Em relação ao eixo temático saberes conceituais estes se dividem em dois subeixos que são: conhecimentos técnicos e conhecimentos críticos.

Sobre esta estrutura dos saberes (conteúdos) se destacam dois momentos. O primeiro deles diz respeito à importância de considerar que nem todos os saberes e formas culturais são suscetíveis de constarem como conteúdos curriculares o que necessita desta forma uma seleção rigorosa por parte da escola (LIBANEO, 1994). Tal como destacado no referencial a incorporação de tais conteúdos (saberes) no contexto escolar deverá ser ocasionada pela análise crítica-reflexiva dos próprios professores da rede escolar.

Estes professores, levando em consideração a realidade local, a relevância social, às condições ambientais, estrutural-funcionais e os alunos, poderão selecionar os conteúdos que farão parte da sua disciplina. É evidente que deverão pautar esta seleção pelos princípios orientadores. Do contrário pode-se correr o risco de selecionarem aqueles somente em que tem mais afinidade, ou, continuarem a fazer o que atualmente já fazem, sem alguma reflexão sobre o referencial e sobre a sua própria atuação.

Por outro lado, um segundo momento que se destaca está amplamente focalizado na riqueza peculiar dos conteúdos apresentados (forma e conteúdo). Além da linguagem acessível, do caráter flexível interposto, da descrição do processo orientador para a

Pensar a Prática, Goiânia, v. 14, n. 1, p. 1-14, jan./abr. 2011 
abordagem dos conteúdos, o acervo da cultura corporal exposto como possíveis saberes curriculares denota o patrimônio significativo de práticas corporais a serem tematizadas nas aulas de EF.

Este acervo representa uma ampliação dos conteúdos a serem abordados nos programas curriculares em EF, se comparados aos próprios Parâmetros Curriculares Nacionais (BRASIL, 1997). Incentiva uma transformação da EF no cenário escolar com tendências exclusivamente esportivistas ou de promoção da saúde, para uma EF mais plural, generalista e crítica. O referencial amplia esta oferta por outros saberes a serem vivenciados e aprendidos nas aulas. De certa forma, convertendo-a em uma disciplina escolar. Conferindo assim a própria identidade da disciplina como componente curricular. Isto por que apresenta um significativo conjunto de temas que podem ser abordados e desenvolvidos no âmbito educativo.

No instante que o referencial curricular apresenta dois grandes conjuntos de temas estruturadores, conferem-lhes a idéia de uma dimensão epistemológica e teoria da área. Esta dimensão cria uma identidade sobre o campo de conhecimentos pertencentes à área o que permite estruturá-la. Como conseqüência desta estruturação, se orienta a progressão e organização sistemática dos conteúdos (NEGRELLI, 2005).

Entretanto, é pertinente considerar que

\begin{abstract}
os conteúdos não são objetos naturais se não que se constroem para o ensino, são os resultados de decisões políticas, epistemológicas, cientificas e pedagógicas de um conjunto variado de atores distribuídos em uma escala que vai desde as altas esferas de condução do sistema educativo (suas decisões são mais abstratas, afastadas das práticas reais, mas com um poder simbólico considerável), até os docentes que selecionam cotidianamente aquilo que ensinarão em suas aulas (ROZENGARDT, 2005, p. 95).
\end{abstract}

Desta forma, a capacidade de organização e estruturação lógica que o referencial apresenta sobre estes saberes (conteúdos) demonstra o esforço de mediatizar tais conhecimentos para o contexto escolar. Um significativo empenho de abordá-los como saberes escolares a serem produzidos, reproduzidos e transformados.

Contextualmente os conteúdos da EF incluem "um conjunto amplo de atividades corporais e motrizes efetivadas em diferentes âmbitos institucionais: educação, esporte, saúde, lazer e tempo livre e outras que se ampliam segundo a dinâmica social, as demandas do mercado e/ou do estado" (ROSENGARDT, 2005, p. 95). Não obstante, no referencial estes conteúdos apresentados representam uma parcela desta dinâmica da cultura humana. Parcela esta que poderá ser constantemente ressignificada, revista e revisitada. Isto em virtude da própria realidade social, seja ela na cultura geral ampla e/ou na cultura específica sobre as práticas corporais, em seus diferentes modos e formas, estar em permanente transformação.

Os mapas conceituais simulam uma tentativa de estruturação lógica destes saberes escolares específicos da área. Eles apresentam uma sistematização (horizontal/vertical) dos conhecimentos que devem ser abordados em cada etapa escolar (seja por série ou ciclo de aprendizagem). Vê-se nestes mapas conceituais, sobre cada eixo temático, uma importante tentativa de estabelecer uma progressão lógica na aprendizagem. E superar o que Kunz (1994) denominou de "bagunça interna" da própria área, ao tornar a prática pedagógica responsável por mediatizar conhecimentos acerca do universo da cultura humana.

Pensar a Prática, Goiânia, v. 14, n. 1, p. 1-14, jan./abr. 2011 
Os currículos escolares, mais especificamente, os componentes curriculares, se concretizam na escola por meio da sua dinâmica curricular, ou seja, de construção de uma base material capaz de realizar o projeto de escolarização do homem (COLETIVO DE AUTORES, 1992). A elaboração destes mapas conceituais, presentes no referencial acaba por atender dois pólos ${ }^{8}$ que estão presentes neste processo de escolarização e, por conseguinte, da composição de um componente curricular.

O primeiro deles está relacionado ao trato com o conhecimento. O referencial apresenta critérios de seleção dos saberes a serem tematizados, uma organização das matérias ao longo dos anos escolares, manifesta também uma sistematização lógica e metodológica do saber escolar alicerçado na síntese entre a dimensão cientifica do conhecimento universal e o saber experiencial vivenciados pelos professores e alunos. Já o segundo se estabelece na dimensão da organização escolar, visto que, apresenta um tempo e um espaço pedagógico para a apreensão ativa da aprendizagem. No que concerne ao apresentado nos mapas, os alunos poderão vivenciar e realizar interpretações da realidade que estejam inseridos.

Por fim, temos as estratégias de ensino ao qual denotam esta tentativa de facilitar a aquisição e apreensão destes conhecimentos. São apresentadas algumas formas de abordagem que poderão contribuir para com o processo de ensino-aprendizagem, para a construção e desenvolvimento das aulas propriamente ditas. Estratégias estas que surgem das experiências da prática educativa, ou como diria Pérez-Gomes (1992), da prática reflexiva da própria ação docente ${ }^{9}$. Este ato reflexivo do docente é capaz de auxiliá-lo a enfrentar suas limitações pessoais e coletivas (GOMES-DA-SILVA, 2009).

De certa forma, o referencial curricular reforça a importância desta experiência para com a elaboração e desenvolvimento dos conteúdos. Ele indica algumas estratégias que poderão ser modificadas e, principalmente, ampliadas, pelos docentes, de acordo com a sua realidade de intervenção. Neste sentido, é o professor no seu ambiente de intervenção pedagógica quem delimitará a sua ação docente. É ele quem dará a profundidade necessária acerca dos conteúdos a serem desenvolvidos, assim como a utilização de suas estratégias pessoais para o ensino.

\section{Considerações finais}

No âmbito da cultura escolar, os problemas da EF não se restringem apenas a sua própria prática pedagógica, mas se estabelecem em torno do contexto escolar. Professores e alunos tendem a trabalhar em uma concepção dialógica de construção de um novo conhecimento. Todavia, para que isto ocorra é imprescindível que a disciplina EF se torne um componente curricular efetivamente presente no cenário escolar. Diante desta possibilidade se desenvolve a expectativa da organização de um trabalho pedagógico pautado nas relações sociais e na dinâmica cultural.

Apoiado nas pedagogias críticas da educação, o referencial curricular gaúcho caminha na direção de conseguir abordar temas pertencentes ao entorno escolar. Temáticas que estão presentes na cultura humana e que podem passar a ser problematizadas, produzidas e transformadas no interior da escola. Esta tematização

\footnotetext{
${ }^{8}$ O coletivo de autores (1992) apresenta um conjunto de três pólos para a composição das bases de um currículo escolar. Estes pólos são: i) trato com o conhecimento; ii) organização escolar; iii) Normatização escolar.

${ }^{9}$ Para a autor uma epistemologia da prática reflexiva esta relacionada a: i) reflexão-na-ação, ii) reflexãosobre-a-ação; iii) reflexão-sobre-a-reflexão-na-ação
}

Pensar a Prática, Goiânia, v. 14, n. 1, p. 1-14, jan./abr. 2011 
10

10.5216/rpp.v14i1.9769

poderá possibilitar o desenvolvimento de um aluno mais crítico, reflexivo e autônomo. Um discente atento as transformações e manifestações sócio-culturais. O que, de certa forma, incorrerá em uma apropriação e ressiginificação crítica da realidade na qual está inserido. A interatividade entre docentes e discentes, como trocas de experiências e vivencias, reforçará esta possível reestruturação da dimensão social-cultural.

Objetivando tal reinvenção da realidade o referencial apresenta um conjunto significativo de saberes a serem abordados na disciplina EF. Conhecimentos estes que acentuam a idéia da transformação da disciplina em componente curricular que passa a ter matéria a ser ensinada.

Sendo assim, o referencial curricular gaúcho consegue, no âmbito da EF, caminhar na direção de firmar um avanço para a sistematização desse componente curricular. A elaboração de mapas conceituais, o estabelecimento de uma progressão estruturada dos conteúdos a ser abordada ao longo dos anos escolares, a organização de um tempo pedagógico para a tematização de tais conteúdos, a possibilidade do desenvolvimento das competências e habilidades indicam esta transformação.

Contudo, todo esse avanço teórico-metodológico proposto só ganhará concreticidade quando estiver sendo planamente vivenciado, debatido e reformulado por parte dos professores das escolas da rede estadual do Rio Grande do Sul. Do contrário, o documento poderá não aglutinar grupos em torno de uma pauta comum, não favorecer a apropriação e sua reformulação por parte dos professores mobilizados na reflexão da prática (APPLE, 1994). Desta feita, o referencial gaúcho pode se tornar um manual didático, um discurso dominante, um conhecimento oficial que silencia o movimento e a organização dos trabalhadores da educação.

\section{REFERÊNCIAS}

APPLE, M. A política do conhecimento oficial: faz sentido a idéia de um currículo nacional? In: MOREIRA, A.F.B.; TADEU DA SILVA, T. (Orgs.). Currículo, cultura e sociedade.SP: Cortez, 1994, p.59-92.

BETTI, M. Educação Física. In: GONZELEZ, F; FENSTERSEIFER, P. Dicionários Crítico de Educação Física. Ijuí: Unijuí, 2005. p. 144-150.

BRACHT, V. Educação Física \& Ciência: Cenas de um casamento (in) feliz. $2^{\mathrm{a}}$ Ed. Ijuí: Unijuí, 2003a.

(Org). Pesquisa em ação: educação física na escola. Ijuí: Unijuí, 2003b.

- Cultura Corporal, Cultura de Movimento ou Cultura Corporal de Movimento: In: SOUZA JÚNIOR, M. (Org). Educação Física Escolar: Teoria e política curricular, saberes escolares e proposta pedagógica. Recife: EDUPE, 2005. p.97-106.

BRASIL, República Federativa do. Decreto n. 69.450, 01.11.1971.

República Federativa do. Lei n. 9.394, 20.12.1996.

Pensar a Prática, Goiânia, v. 14, n. 1, p. 1-14, jan./abr. 2011 
11

10.5216/rpp.v14i1.9769

, República Federativa do. Secretaria de Educação Fundamental. Parâmetros

curriculares nacionais: Educação Física. Brasília. MEC, 1997.

, República Federativa do. Lei n. 10.328, 12.12.2001.

CAStellani FILHO, L. Política educacional e Educação Física. Campinas: Autores Associados, 1998.

COLETIVO DE AUTORES. Metodologia do Ensino de Educação Física. São Paulo: Cortez, 1992.

DAOLIO, J. Cultura. In: GONZÁLEZ, F; FENSTERSEIFER, P. Dicionários Crítico de Educação Física. Ijuí: Unijuí, 2005. p.106-108 .

DARIDO, S. Os conteúdos da Educação Física Escolar: Influências, dificuldades e possibilidades. Perspectivas em Educação Física Escolar, Niterói, v.2, $\mathrm{n}^{\mathrm{o}}$ 1(suplemento), 2001. p 5-21. _ Conteúdos Escolares. In: GONZÁLEZ, F; FENSTERSEIFER, P. Dicionários Crítico de Educação Física. Ijuí: Unijuí, 2005. p. 97-99.

FORQUIN, J. C. Escola e Cultura: as bases sociais e epistemológicas do conhecimento escolar. Porto Alegre: Artes Médicas, 1993.

FREIRE, J.B; SCAGLIA, A.J. Educação como prática corporal. São Paulo: Scipione, 2003.

GOMES-DA-SILVA, P.N. Prática de ensino em educação física: por uma formação do professor-pesquisador. In: Educação Física: conhecimento e saber escolar. João Pessoa, Paraíba: UFPB, 2009. p.103-128.

GONZÁLEZ, F, J. Projeto Curricular em educação física: o esporte como conteúdo escolar. In: REZER, R. (org): $O$ fenômeno esportivo: ensaio crítico-reflexivos. Chapecó: Argos, 2006. p. 69-109.

A identidade profissional em Educação Física: uma mirada de sua transformação. Revista Digital, Buenos Aires, ano 13, n. 120, maio, 2008. Disponível em: $\quad<\quad$ http://www.efdeportes.com/efd120/a-identidade-profissional-em-educacaofisica.htm $>$. Acesso em: 14 de abril de 2010.

GONZÁLEZ, F. J; FRAGA, A. B. Referencial Curricular de Educação Física. In: RIO GRANDE DO SUL. Secretaria de Estado da Educação. Departamento Pedagógico. (Org.). Referencias Curriculares do Estado do Rio Grande do Sul: Linguagens, Códigos e suas Tecnologias. 1 ed. Porto Alegre: SE/DP, 2009, v. 2, p. 112-181.

GRESPAN, M.R. Educação Física no ensino fundamental: Primeiro ciclo. Campinas: Papirus, 2002.

Pensar a Prática, Goiânia, v. 14, n. 1, p. 1-14, jan./abr. 2011 
12

10.5216/rpp.v14i1.9769

HILDEBRAND, R. Educação física aberta à experiência: uma concepção didática em discussão. RJ: Imperial Novo Milênio, 2009. educação física. v.1,2. Ijuí: Unijuí, 1998, 2002.

(Org.). Didática da

HILDEBRAND, R. Textos pedagógicos sobre o ensino da educação física. 2.ed. 2003

KUNZ, E. Transformação Didático-pedagógica do esporte. Ijuí: Unijuí, 1994.

LAVILLE, C.; DIONNE, J. A construção do saber. Porto Alegre: ArtMed, 1999.

LIBÂNEO, J.C. Didática. São Paulo: Cortez, 1994.

MOREIRA, A.F.B.; TADEU DA SILVA, T. (Orgs.). Currículo, cultura e sociedade. SP: Cortez, 1994.

NAHAS, M. V. Atividade Física, Saúde e Qualidade de Vida: conceitos e sugestões para um estilo de vida ativo. 4a .ed. Londrina: Midiograf, 2006.

NEGRELLI, J. M. Metodologia de ensino da Educação Física. In: GONZÁLEZ, F; FENSTERSEIFER, P. Dicionários Crítico de Educação Física. Ijuí: Unijuí, 2005. p.276-277.

OLIVEIRA, A. Educação Física no ensino médio - Período noturno: Um estudo participante. 1999. Tese (Doutorado em Educação Física) - Curso de Educação Física, Unicamp, Campinas, 1999.

OLIVEIRA, M. N. de (Org). As políticas educacionais no contexto da globalização. Ilhéus, Editus, 1999.

PÉREZ-GOMEZ, A. I. O pensamento prático do professor: a formação do professor como profissional reflexivo. In: NÓVOA, A (Org.). Os professores e sua formação. Lisboa: Dom Quixote, 1992. p. 93-114.

PERRENOUD, P. Construir competências é virar as costas aos saberes? Revista Pátio, Porto alegre, ano 3, nº11, Nov. 99/ jan. 2000.

PICH, S. Cultura Corporal de Movimento. In: GONZÁLEZ, F; FENSTERSEIFER, P. Dicionários Crítico de Educação Física. Ijuí: Unijuí, 2005. p. 108-111.

REZER, R; FENSTERSEIFER, P. E. Docência em Educação Física: Reflexões acerca de sua complexidade: Pensar a prática, v. 11, nº 3. p. 319-329, set/dez, 2008.

RIO GRANDE DO SUL. Secretaria de Estado da Educação. Departamento Pedagógico. (Org.). Referencias Curriculares do Estado do Rio Grande do Sul: Linguagens, Códigos e suas Tecnologia. 1 ed. Porto Alegre: SE/DP, 2009

ROSENGARDT, R. Conteúdo. In: GONZÁLEZ, F; FENSTERSEIFER, P. Dicionários Crítico de Educação Física. Ijuí: Unijuí, 2005. p. 94-97.

Pensar a Prática, Goiânia, v. 14, n. 1, p. 1-14, jan./abr. 2011 
13

10.5216/rpp.v14i1.9769

SACRISTAN, J.G.; PEREZ GOMES, A.L. Compreender e transformar o ensino. Porto Alegre: artes Médicas. 2000.

SILVA, A. M. Corpo, conhecimento e Educação Física escolar. In: SOUZA JÚNIOR, M. (Org). Educação Física Escolar: Teoria e política curricular, saberes escolares e proposta pedagógica. Recife: EDUPE, 2005. p. 85-96.

SOARES, C. L; Educação Física Escolar: conhecimento e especificidade. Revista Paulista Educação Física, São Paulo, supl 2, p. 6-12, 1996.

SOUZA JÚNIOR, M. (org). Educação Física Escolar: Teoria e política curricular, saberes escolares e proposta pedagógica. Recife: Edupe, 2005.

\section{THE BENCHMARK OF PHYSICAL EDUCATION CURRICULUM OF THE STATE OF RIO GRANDE DO SUL: A QUALITATIVE ANALYSIS}

Abstract: The article aims at examining the benchmark curriculum of Rio Grande do Sul to the grade Physical Education. This analysis focused on the document itself and the discussion came from the pairing strategy, linking the core meaning with the critical theory of curriculum area. The document constitutes a theoretical construct and methodological innovation and connected with the contemporary requirements for a quality basic education to the extent that a proposed organization of the subjects with criteria for selection and processing of knowledge in a more plural, general and critical. However, in the power relations that make up the training curriculum, the reference may become a textbook and that signals a possible dominant discourse.

Keywords: Culture; Education; Curriculum

\section{EL PUNTO DE REFERENCIA DE LA EDUCACIÓN FÍSICA PLAN DE ESTUDIOS DEL ESTADO DE RIO GRANDE DO SUL: UN ANÁLISIS CUALITATIVO}

Resumen: El artículo tiene como objetivo examinar el plan de estudios de referencia de Río Grande do Sul en grado de Educación Física. Este análisis centró en propio documento y la discusión venía de estrategia de vinculación, que une el significado básico de la teoría crítica de área del currículo. El documento constituye una construcción teórica y metodológica y la innovación relacionada con las necesidades actuales de educación básica de calidad en medida que un proyecto de organización de los sujetos con criterios para la selección y procesamiento de los conocimientos de manera más plural, general y crítica. Sin embargo, las relaciones de poder que conforman los programas de formación, la referencia puede convertirse en libro de texto y que las señales de discurso dominante posible.

Palabras clave: Cultura; La educación; Plan de estudios

Pensar a Prática, Goiânia, v. 14, n. 1, p. 1-14, jan./abr. 2011 
14

10.5216/rpp.v14i1.9769

Endereço para correspondência:

Pierre Normando Gomes-da-Silva

pierrenormandogomesdasilva@gmail.com

Universidade Federal da Paraíba

Centro de Ciências da Saúde - Campus I

Departamento de Educação Física.

Castelo Branco

58000-000 - Joao Pessoa, PB - Brasil

Pensar a Prática, Goiânia, v. 14, n. 1, p. 1-14, jan./abr. 2011 